\title{
Violence Against Women
}

http://vaw.sagepub.com

\section{"But Sometimes I Think ... They Put Themselves in the Situation": Exploring Blame and Responsibility in Interpersonal Violence \\ Suruchi Thapar-Björkert and Karen J. Morgan \\ VIOLENCE AGAINST WOMEN 2010; 16; 32 \\ DOI: $10.1177 / 1077801209354374$}

The online version of this article can be found at: http://vaw.sagepub.com/cgi/content/abstract/16/1/32

\author{
Published by: \\ (9)SAGE \\ http://www.sagepublications.com
}

Additional services and information for Violence Against Women can be found at:

Email Alerts: http://vaw.sagepub.com/cgi/alerts

Subscriptions: http://vaw.sagepub.com/subscriptions

Reprints: http://www.sagepub.com/journalsReprints.nav

Permissions: http://www.sagepub.com/journalsPermissions.nav

Citations http://vaw.sagepub.com/cgi/content/refs/16/1/32 

Interpersonal Violence

\author{
Suruchi Thapar-Björkert' \\ and Karen J. Morgan ${ }^{2}$
}

\begin{abstract}
This article draws on narratives of volunteers working with women who have experienced violence. It explores how institutional discourses nurture a culture of blame and responsibility. Using qualitative data, it examines the ways in which women victims are seen as complicit in their own victimization. An indirect consequence of the blame/responsibility dichotomy is that victims are depicted as deserving their fate. There is, therefore, a culture of resignation in which violence is normalized. It proposes that if institutional practices are embedded in a feminist tradition, they can provide a more sustainable framework for challenging sexual and domestic violence.
\end{abstract}

\title{
Keywords
}

blame, victim support, violence

\section{Introduction}

In this article, we examine some of the processes and mechanisms through which prevalent ideological and social discourses of violence provide legitimacy to the imminent nature of domestic and sexual violence in the United Kingdom. Our article draws attention to the importance of understanding the social contexts and social worlds in which violence and victimization are understood and conceptualized. We argue that these social contexts

\footnotetext{
'University of Bristol, Bristol, UK

${ }^{2}$ Cardiff University, Cardiff, UK

Corresponding Author:

Suruchi Thapar-Björkert, University of Bristol, 12 Woodland Road, Bristol BS8 IUQ, UK

Email: s.thapar-bjorkert@bristol.ac.uk
} 
inform understandings of those supporting victims of violence and thereby contribute to an ideologically dilemmatic situation between a culture of blame, on one hand, and a culture of responsibility, on the other. Drawing on empirical data, we highlight three key themes contributing to this culture of blame and responsibility: First, the burden of responsibility is placed on women for their victimization, and in doing so it absolves the perpetrators from accepting accountability for their own actions. Second, victims of violence are often placed under surveillance and expected to conform to regulated behavior by perpetrators, by those from whom they seek help, and by society at large. Third, we suggest that certain unintentional institutional attitudes may not sufficiently challenge the prevalent discourses toward victims of violence.

The article is structured in the following way: First, we highlight the qualitative methodological approaches that inform the analyses of this article. Second, we provide a background to some of the key feminist debates on domestic and sexual violence. Given the vast amount of literature already available on the topic, in this article, we emphasize those issues that are most relevant to our analysis. Third, we examine some of the discursive frameworks that facilitate a culture of blame and responsibility in relation to women experiencing violence. We believe that there is a dialectical relationship between society and discourse, with society (and culture) both being shaped by and simultaneously constituting discourse (Wodak, 1996, cited in Titscher, Meyer, Wodak, \& Vetter, 2000, p. 146). This we will mainly analyze through the narratives of volunteers working for the U.K. charity, Victim Support (VS). Finally, we conclude by suggesting that a more thorough engagement with feminist research, traditions, and philosophy could lead to a reassessment of some institutional attitudes toward women experiencing violence.

\section{Method}

Our focus for this article is the United Kingdom, and we will draw on discourses deployed by those with particular expertise of working with women victims of violence. We will specifically engage with the narratives of VS volunteers who operate through a network of local charities that provide support to crime victims throughout the United Kingdom. ${ }^{1}$ For the research on which this article is based, a total of $15 \mathrm{VS}$ volunteers, aged between 22 and 65, were interviewed, 13 of whom were women and 2 were men-a reflection of the gender split among outreach support volunteers in the organization as a whole (VS, 2005). According to the 2001 Census, the geographical area in which most of the research was conducted has a population that is $97.6 \%$ White, 1.4\% Asian or British Asian, $0.8 \%$ mixed race, $0.7 \%$ Black or Black British, and $0.5 \%$ Chinese or Other (National Statistics Online, 2001). During 2003/2004, the ethnic breakdown of VS volunteers in the area scheme in which the research was conducted was $92.9 \%$ White and $7.1 \%$ from Black and minority ethnic groups (VS, 2005). In the specific branch from which the volunteers who participated in the research were recruited, at the time of the research, the breakdown of volunteers was $100 \%$ White. Not surprisingly therefore, all the volunteers who participated in the research were White British. Suffice it to say, however, that those interviewed for the research are not intended to be seen as a representative sample of the United 
Kingdom as a whole but are rather intended to illustrate the type of attitudes prevalent within certain communities.

With the agreement of the relevant VS branch coordinator, the volunteers were approached by the second author who had herself worked as a VS volunteer for several years. All those approached had previously been met by the second author at various meetings and training events, although none of them was known well and the relationship with all of them was little more than that of casual acquaintance. At a volunteers' meeting, the second author talked a little about the research and made a general request for participants. However, to avoid the possibility that any of the volunteers may have felt compelled to agree to take part by the fact that the scheme coordinator was present at the meeting (see Tisdall, 2003), they were subsequently approached individually and in private. Of the 20 volunteers asked, all agreed to be interviewed. In practice, however, it was not possible to interview all those who agreed for a variety of reasons, such as illness, personal problems, and leaving VS.

All but two of the interviews were conducted in the volunteers' own homes (the remaining two were conducted in the second author's home). All volunteer-participants readily agreed that the interviews could be recorded with none expressing any concerns about confidentiality (although two did request that the recorder be switched off for a few minutes during their interviews as they gossiped about colleagues). At the beginning of each interview, informed consent was obtained, with the nature of the research being explained and confidentiality issues discussed. It was reiterated that the participant was free to refuse to answer any questions, request that the recorder be turned off, and/or terminate the interview at any time. ${ }^{2}$ None of the participants expressed concerns about any of these issues. However, it is not clear whether their particularly relaxed attitudes were due to the fact that they knew the second author was also a volunteer with VS and thus used to dealing with sensitive and confidential matters or because they felt that they were talking about others rather than anything particularly personal.

Furthermore, although the interviews with the volunteer-participants were intended to be comparatively loosely structured, it is problematic to refer unreflexively to unstructured interviews. ${ }^{3}$ Nevertheless, these interviews, to a large extent, were driven by the participants and provided the freedom to explore any unexpected areas that arose throughout the discussion. The interview data were analyzed bearing in mind Ruthellen Josselson's (2004) reworking of Ricoeur's (1981) hermeneutics of faith, in which the central process involves understanding the research participants' narratives from his or her point of view rather than regarding them with suspicion. ${ }^{4}$

\section{VS}

Although VS operates as an independent organization, at the time of the research, it received the majority of its funds from the U.K. government's Home Office and the rest from private fund-raising, local council grants, or sources such as the European Commission or Lottery funding (VS, 2006). The issue of funding is an important one, not least from a feminist perspective. As Radford and Stanko (1996) note, "despite the commitment of some feminist volunteers within victim support, the philosophy of the national organisation, 
Victim Support, is actively non-feminist" (p. 74). This has to be located within the wider political climate of support, whereby "respectable" groups such as VS are supported, often at the expense of "more radical, anti-racist and pro-feminist groups" such as Women's Aid and Rape Crisis (Williams, 1999, p. 388). ${ }^{5}$ In fact, arguably, the Victim's Charter ${ }^{6}$ maintains the government's policy of marginalizing "pro-feminist, anti-racist and single issue, self-help victims organisations by the simple expedient of ignoring their existence" (Williams, 1999, p. 394).

Victim Support's remit at the time the research was conducted involved offering a range of services to victims of crime:

- providing free and confidential, emotional, and practical help and advice;

- liaising with criminal justice agencies on behalf of victims;

- coordinating support from other agencies and community organizations;

- carrying out research and public education into issues affecting crime victims;

- lobbying government on behalf of crime victims and witnesses;

- providing support via the Witness Service (sister organization) to witnesses attending court (Crown or Magistrates' Courts) to give evidence;

- liaising with the Witness Service to provide a continuation of service and support for victims giving evidence (National Audit Office, 2002; VS, 2006). ${ }^{7}$

The majority of volunteers with the organization provide support to victims of a variety of incidents, ranging from burglary to the most serious violent crimes including domestic and sexual abuse. At the time the research on which this article draws was conducted, most of the work carried out by volunteers was outreach support - going out to see victims in their homes. More recently, however, there has been a shift toward providing helpline support with only victims of more serious crimes tending to receive personal visits.

The strength of the VS role and of particular relevance for this article, we suggest, is the fact that the volunteers may be seen as expert-amateurs. Although they lack professional involvement with victims, though some volunteers may of course have a relevant professional capacity in addition to their voluntary role (in their paid employment, for example, as social workers), they are provided with specialist training that is intended to highlight the problems and issues faced by victims of crime. Accordingly, the volunteers must be seen as somewhere between those who have little or no awareness of issues relating to victims of violence (other than the commonsense understandings acquired through routine social interactions) and those who have acquired knowledge through their own victimization. It should be pointed out, of course, that the motivation for some of the volunteers working with VS is the fact that they have themselves experienced some form of victimization. The rationale for the provision of support through volunteers is that they help to restore faith in the local community. The fact that their work is unpaid is seen as going some way toward redressing the balance as regards the harm the victim has had caused to them (Personal communication, VS trainer, March, 2003).

It is worth noting that as compared to VS, victim advocacy (as it is called in the United States $)^{8}$ seems a more formal, proactive system of support. Dunn and Powell-Williams (2007) 
suggest that victim advocacy in the United States has "recently become a profession in addition to a calling" (p. 978). It has therefore become increasingly professionalized, using paid staff rather than volunteers, unlike the explicitly volunteer-driven focus of VS. However, recent changes within VS in the United Kingdom have meant a greater emphasis on "advocacy," which is described as being "about taking action to help people say what they want, claim their rights, represent their interests and obtain the services they need" (VS, 2007 , p. 60). Still, at present, the provision of an explicit advocacy service is not widespread within the organization.

McDermott and Garofola (2004) discuss "follow-up advocacy" and "victim safety checks," which they say "involves intrusion into the lives of battered women who did not seek services" (p. 1255). This would not happen in the United Kingdom's VS system because support is never imposed on a victim who does not request it. VS volunteers may work with a victim of domestic violence irrespective of the fact that the police or other agencies are involved and would not seek to involve the wider criminal justice system without the victim's explicit agreement. ${ }^{9}$

\section{Contexts of Violence}

The issues that inform the work of VS in the United Kingdom (and victim advocacy in the United States) have to be located within the broad interventions made by feminist research, which has increasingly questioned the gaps in the conceptualization and in the experience of violence. ${ }^{10}$ Feminist interventions, we would argue, have pushed the debates forward in several key areas. First, while foregrounding familiarity as a central feature of domestic and sexual violence (Boateng, 1999; Maynard, 1993; Mezey \& Stanko, 1996; Smart, 1989), the debates have broadened definitions of violence to incorporate a range of behaviors including emotional and psychological as well as physical abuse, thus shifting the focus away from the "battered woman" to look at "lesser" physical forms of abuse that damage women and children psychologically and which if not checked can set the stage for more extreme incidents (hooks, 1997, p. 282; also see Lamb, 1999; Loseke, 1999). For example, hooks (1997) argues that an overfocus on forms of extreme physical violence leads to an acceptance of everyday physical abuse such as occasional hitting (also see Morgan \& Thapar-Björkert, 2006). Second, they have highlighted not only the invisible and often insidious workings of male power and control within public and private spaces (cf. Corrin, 1996; Dobash \& Dobash, 1997; Hester, Kelly, \& Radford, 1996; Kelly, 1988, 1996; Maynard, 1993; Radford \& Russell, 1992) but also the endemic and routine nature of violence (Stanko, 1985, 2003, 2006). Thus, it is not necessarily the tangible act of violence, which imposes a form of social control over women, but the "internalization through continual socialization" of the possibility of violence (Smart \& Smart, 1978, p. 100). Third, many writers suggest that violence against women should be located in a broad sociostructural context. Pahl (1985) points out that violence against women can be legitimized by society at large to the extent that it becomes possible to deny that domestic violence takes place at all, or to claim that if it does happen, it is only applicable to "unusual or deviant couples" (p. 11). As Stanko (2006) argues, context governs how seriously we as a society respond to 
incidents of violence as (un)“acceptable” (p. 545). In fact, one of the pivotal premises of the Zero Tolerance Campaign against gendered violence in the United Kingdom was the need to "change societal attitudes towards . . . violence by making it socially unacceptable, and by challenging the norms ... which . . . sustain it" (Cosgrove, 1996, p. 189). Fourth, debates suggest that mere theorizing is insufficient, and ideas and strategies produced as a result of investigations of women's experiences should inform as well as be informed through feminist activism (McLaughlin, 2003). This, it was argued, would also enable women who have been abused to say what they want and need (Hague \& Mullender, 2006; Kelly, 1996). As Hague and Mullender (2006) note, "if services addressing domestic violence are to ... . effectively meet abused women's needs, then the views of those using them need to be heeded" (p. 568).

A part of the process of exposure has involved the explicit naming of violence and abuse by men to ensure that women's experiences of violation should not be left literally unspeakable (see Kelly, 1996). Thus, the necessity of a feminist approach that was characterized by consciousness raising and activism was emphasized. This tradition of consciousness raising coupled with the need for a sympathetic societal response led to the creation of the battered woman syndrome in the 1980s and 1990s in America (Loseke, 1992). This syndrome was viewed by many as a form of cultural compromise (Rothenberg, 2003) because although it enabled advocates to achieve their goals of public sympathy, it also created a homogenous construct of the battered woman. The "battered woman," a "long-suffering victim," and a "mainstay client of therapists" was absorbed by the "consuming public" (Lamb, 1999, p. 116). For example, Loseke (2001) argues that support groups in the United States, through their organizational practices, promulgate the identity of a battered woman even though women victims' lived realities are often at odds with the template of the formula stories (also see Kendrick, 1998). ${ }^{11}$ She suggests that "women's talk about their lived realities often complicates, even subverts, the straightforward narratives of the formula story of wife abuse" (Loseke, 2001, p. 110). Institutionally preferred narratives, as Holstein and Gubrium (2000) claim, lead to an "institutionalization of the selves" (p. 16).

Building on these arguments our article focuses on the tension between institutional discourses and individual perception and how these can contribute to an understanding that sometimes violence is natural, normal, to be expected, and/or understandable. For example, specific discourses that imply that women are responsible for their victimhood are reflected in statements such as "she asked for it." Separating attitudes encapsulated in statements such as this from more professional attitudes of nonblame may not always be a straightforward or easy matter. We question, therefore, whether unintentionally judgmental attitudes to women victims of violence may not be inherent in the understandings of some of those engaged in combating the effects of violence, despite their genuine desire to provide support.

\section{Culture of Blame and Responsibility}

In this article, our intention is not to deny the enabling and autonomy enhancing potential of institutional practices within statutory and voluntary organizations toward women who have experienced violence. However, we also want to acknowledge analyses that suggest 
that these institutions may fail some women (Westlund, 1999; see also Hague, 1998; Hague \& Mullender, 2006; Malos, 2000).

\section{Shouldering the Burden of Responsibility}

Interventionist strategies for dealing with domestic abuse (such as the Duluth model in Minnesota in the United States) have alerted practitioners and activists dealing with all forms of interpersonal violence to the need for a coherent philosophical approach, which focuses on victim safety, holds offenders accountable, and eliminates victim blaming (Pence \& MacMahon, 1999).

In relation to sexual violence particularly, it is argued that women are often blamed or seen as complicit in the sexual offenses against them (Berns, 2001; Corrin, 1996; Hague, 1998; Lamb, 1996; Lea, 2007; Maynard, 1993; Morgan, 2006). The attention and questioning therefore shifts toward the women rather than to men's violence. Thus, an environment of victim blaming and normalization of violence is created in which women feel unable to report crimes of violence against them. As Bunch and Carrillo (1992) suggest, "women are socialized to associate their self-worth with the satisfaction of the needs and desires of others and thus are encouraged to blame themselves as inadequate or bad if men beat them" (p. 18). Women who are victims of male violence find "breaking the silence" stigmatizing because they are often perceived by others as "fallen women who have failed in the 'feminine' role" (hooks, 1997, p. 283).

Nancy Berns (2001) argues that political discourses on violence often shift the focus from abusers to the victims. She argues that the popular representation in, for example, newspapers, magazines, or television reports is responsible for constructing and reproducing images of domestic violence, which in turn influence the way individuals "construct their own conceptions of what is normal and acceptable" (p. 263; see also Berns \& Schweingruber, 2007, p. 247). She refers to this perspective as patriarchal resistance and usefully highlights three implications in this resistance discourse: the normalization of intimate violence, the diversion of attention from men's responsibility in violence, and the distortion of women's violence.

Although we agree with Berns that the argument that men and women are equally violent is often used in "de-gender(ing)" the problem of domestic violence, it is still important to understand how both men and women are complicit in "gendering the blame" through the "refram[ing]" of discourses in such a way as to "obscur[e] men's violence while placing the responsibility on women" (Berns, 2001, p. 262). To illustrate our point, we will look at some of the ideas articulated by VS volunteers who, we suggest, are potentially uniquely placed to resist and challenge some of the perceptions and stereotypes relating to women victims of violence. The increased level of understanding acquired by the volunteers that places them in such a position was appreciated by at least some of the volunteers interviewed, as expressed here by Sally:

I think training and talking to people have opened my eyes to what goes on [in relation to victim blaming]. I mean I think perhaps people that are on the outside and 
don't have more information maybe don't see it quite that clearly. (Sally, VS volunteer; our emphasis)

As a result of their training, these volunteers see themselves as being in a position to help the victim come to terms with what has happened to them and thus to empower the victim, enabling him/her to continue with their lives. For example,

She gradually didn't need me. Which I was really pleased about. I mean I was glad when she said she didn't need me because I thought that was good. She's - she's moving forward, isn't she? She's coping for herself. (Sally, VS volunteer)

And a little later into the same interview,

All their self-esteem is on the floor. So I put quite a lot of effort into telling them that they're not useless and that they really are perfectly good human beings, and you know when they tell me anything that was really good that they've done, I do sort of say "that was really good what you did. That was brilliant wasn't it?" . . Because it's horrendous the things they've come through. (Sally, VS volunteer)

Whereas in an interview with another volunteer,

Researcher: When you're with a victim, how do you know or when do you feel that - that it's been successful? That you've done a good job?

Yvonne: At the end, I feel. When you're saying "bye-bye". And then they've suddenly turned round and said "thanks, that's really helped me." And they're smiling and ... I think if they've smiled ... they're thinking about what I'm saying and that might just give them enough confidence to maybe to do something. . . . And then that . . . would make me feel better. If I walked out and that lady was still — or that man — was still sat there with a solemn face, then I would think I haven't done it. I haven't got them to think the other way. They're still thinking that they're still in a bottomless pit. If I walked out and they looked happy, then I think they're thinking about this. It's just enough to give somebody that little bit of confidence to think they can step over it. And find their own way out. Somehow. (Yvonne, VS volunteer)

The VS volunteers aimed to make their clients feel "not useless" and help them out of a "bottomless pit." Similarly, Dunn and Powell-Williams (2007), in their interviews with domestic violence victim advocates in a midwestern state in the United States, also state that a central aspect of the advocates' work is to make clients realize that they have choices because many come in feeling defeated.

In many respects, the relationship between the VS volunteer and the victim (or client) involves much the same forms of social interactions as those that may develop in research interviews that involve "differing aspects of social interaction such as power, friendship, 
reciprocity and shared understandings" (Birch \& Miller, 2000, p. 190). The exact form of the volunteer/victim relationship is somewhat confused therefore, with a blurring of roles between counselor, friend, and various other positions in between. Most volunteers seemed clear that their role was to listen rather than to push for information. For example, Sally commented, "She didn't want to talk details and I wasn't probing. Because it's not what we do, is it?"

However, this blurring of boundaries has raised concerns in the past, with some VS volunteers feeling that they were being expected to take on too much of a counseling role, despite the fact that the majority are not trained counselors (Morgan, 2005). One of the workshops at the 1998 National Conference discussed whether VS is moving to a counseling role and whether it is appropriate. Key points to come out of the discussion were that VS volunteers

provide an immediate, vital response and have a specific role to fulfil, which is not counseling. VS visitors provide a good listening ear, a non-judgemental lasting relationship, empowerment and confidentiality, and they help victims to make informed choices as well as practical information, liaison $[$ sic $]$ with other agencies, as well as possible referrals to counseling. (Victim Support Magazine, 1998, p. 7) ${ }^{12}$

Most of the volunteers recognized that to restore the victim's sense of self-worth, they should be encouraged and supported in avoiding the feelings of self-blame that affect many such victims. In other words, in keeping with the VS "non-blame" rhetoric, and as pointed out by one of the interviewees quoted below, the intention is to empower the victim to acknowledge that "the only person to blame for a crime is the perpetrator" (Spackman, 2000, p. 66):

First of all you just have to let them talk. And then sort of suggest that perhaps it's not their fault and you know, if you really think about it, did you do anything wrong? So get their train of thought actually working another way rather than let them sort of think that they're to blame all the time because that is very often what's been taken away from them - is the way to think for themselves ... you're trying to help them get back upon that ladder and think for themselves. (Olive, VS volunteer)

Nevertheless, despite their training and their evident sincerity in supporting and encouraging women victims of violence, it could also be suggested that the volunteers struggle with the idea that perpetrators of violence are solely to blame for their actions. Statements of those interviewed indicated that some believe that there are occasions when women victims, to some extent, are accountable for what has happened to them. For example, women who transgress acceptable boundaries of dress, behavior, or femininity may be seen as complicit in what has happened to them - as individually responsible for their fate. Weaver (1998) notes that it has become apparent that "women are taught to believe it is their individual responsibility to restrict and censure their activities so as to avoid becoming the victim of [sexual violence]" (p. 262). As Emma (VS volunteer) stated, to avoid violence, "you've got to be careful now wherever you go and ... like work your route out and know where you're going to go and all that sort of thing." 
Although the VS volunteers are certainly not concerned with blaming the victims, they do seem to have taken on board the wider societal discourses of, to use Berns' (2001) term again, "patriarchal resistance" or "gendering" the blame. So, when directly asked about blame, the responses were as follows:

No, I don't think the victim's to blame. Only the aggressor. (Olive, VS volunteer)

No. I can't think of any reason [the victim is to blame]. No. (Ivy, VS volunteer)

[The victim is] not to blame, no, no. (Emma, VS volunteer)

Umm. Not really. No. Umm ... (Sam, VS volunteer)

I don't — no, I don't think there is any justifiable reason for a man to attack a woman physically or sexually. No, I couldn't justify that. Ever. (Sally, VS volunteer)

However, there were also statements that directly contradicted those quoted above:

But sometimes I think ... they put themselves in the situation. (Edna, VS volunteer)

No, I don't think you can be blamed, no. But I think you-you need to look after ourselves [sic] more. (Emma, VS volunteer)

So I-you know-I'm not a subscriber to the view that women do bring it on themselves, although sometimes I think people don't know when to stop and they don't know when to shut up! (Sally, VS volunteer)

These conflicting statements do not mean that the volunteers are attempting to be misleading about their attitudes, and it is certainly not our intention to suggest that there was any element of subterfuge in the volunteers' discourses. However, statements such as this do reveal that it is possible to share different, mutually incompatible ideologies, which have to be negotiated and managed (Van Dijk, 1997). We also believe that training that fails to take into account feminist perspectives may also fail to challenge traditional gender-role beliefs that "are more likely to attribute responsibility to the victim, whilst those holding less traditional [gender]-role beliefs are less likely to attribute responsibility to the victim" (Lea, 2007, p. 497). The training provided to VS volunteers and the resource pack made available to those supporting victims of domestic violence state that the volunteers should "make sure that the responsibility for the perpetrators' behaviour rests with them and is not made the responsibility of the service user [victim]". In other words, "if patterns of abuse arise, some people will assume that they are to blame . . don't collude with these thoughts ... [and] instead explain that no one is ever to blame for abuse" (VS, 2003, p. 23). However, there is no real attempt to address the roots of a victim-blaming culture and the ways in which it may be sustained by patriarchy. Thus, 
although the volunteers may well see themselves as becoming more enlightened as illustrated by Sally's quote earlier in the article, it is apparent that this is insufficient to overcome entrenched beliefs.

These internal arguments or ideological dilemmas (Billig et al., 1988) may be revealed through discourse and discursive practices and arise from the contrary themes within common sense (Billig et al., 1988). Ideology, Billig et al. suggest, takes two forms, intellectual and lived. The former consists of a "system of political, religious or philosophical thinking," whereas lived ideology is described as "society's way of life" (p. 27); in other words, the everyday aspects of life, including commonsense, that govern everyday life. Intellectual ideological processes tend to be coherent formalized forms of thought, "an internally consistent pattern" that enables thoughts and values together to construct a "total mental structure" (Billig et al., 1988, p. 29). So, in terms of the initial response of many of the volunteers interviewed, the conscious acceptance of the VS philosophy that "the victim is not to blame" forms part of the volunteer's intellectual ideology. However, a dilemma arises in respect to a commonsense understanding of the world. It makes sense, for example, for women to avoid walking alone at night in certain areas or that women should try not to wind up their partners when they know them to be potentially violent, particularly when the men have been drinking. Consequently, for VS volunteers, the tensions between the intellectual ideology (the nonblame rhetoric) and the lived ideology (the commonsense knowledge, reinforced by public discourse, that it is women's responsibility to avoid violence, rather than men's responsibility to avoid committing violence) results in the simultaneous possession of opposing views. Emma, as quoted above, for example, notes that women victims of violence are not to blame for their own victimization, but she continues,

But I think she's opening herself up to-you've got to be careful now wherever you go and umm you know they say like work your route out and know where you're going to go and all that sort of thing. (Emma, VS volunteer)

Women, therefore, have to plan where they go, consider possible dangers, and select the safest routes (see also Gardner, 1990; Morgan \& Thapar-Björkert, 2006; Stanko, 1990). The volunteers' understanding that women should not be blamed and should be able to go where they want is therefore at odds with their commonsense knowledge of the world and its dangers for women.

Billig et al. (1988) see that ideological dilemmas as revealed through discursive practices illustrate that individuals do think about what they know. Indeed, it is through the possession of "opposing themes" that "ordinary people [are able] to find the familiar puzzling and therefore worthy of thought" (p. 143). Fairclough (1995) also points out that

it is quite possible for a social subject to occupy institutional subject positions which are ideologically incompatible, or to occupy a subject position incompatible with his or her overt political or social beliefs and affiliations, without being aware of any contradiction. (p. 42) 
So examining the volunteers' narratives in relation to the central questions of whether they challenge or support discourses of blame and how far they are able to accept or refute the notion reveals, as noted above, a tension between the nonblaming rhetoric and commonsense understandings of the causes and consequences of violence against women. ${ }^{13}$ Two themes that constituted these discourses were the role of alcohol in violence and the choice available to women victims to leave an abusive relationship.

Blame, alcohol, and lack of control. It is widely acknowledged among health and policyrelated researchers that alcohol consumption can be a major contributor to intimate partner violence (Finney, 2004). However, it is also recognized that individual and societal beliefs that alcohol causes aggression can encourage violent behavior after drinking and the use of alcohol as an excuse for violent behavior (Field, Caetano, \& Nelson, 2004). Often intoxication is invoked as a postoffense excuse (Ollett, 1994). Several of the volunteers referred to alcohol as a contributory feature in the escalation of violence. Volunteers referred to the way in which it apparently causes the drinker (apart from one reference, they all referred to the drinker being the perpetrator, rather than the victim) to somehow lose control, to become another type of person. Almost all of those who mentioned alcohol remarked on the fact that the drinkers were actually likeable people and that the alcohol seems to have changed some essential part of their nature. So, for example, Ray, who was particularly adamant that drink causes violence said,

I personally know people who - meet them when they're sober and they're completely different people to when they're drunk, you know? Or when they've got some alcohol in them. (Ray, VS volunteer)

Others, although perhaps not quite as adamant as Ray that alcohol is a major factor in violence, were still fairly forceful and yet still blamed the alcohol itself rather than the drinker.

They're lovely when they're sober. I think drink's got a lot to answer for. (Edna, VS volunteer)

But that is often the result of drinks - or drugs and they're out of control. But they're not totally out of control because they still know what they're doing. But . . they're not the same person that they are when they're sober or not on whatever it is they're on. And it alters their behavior and their character. (Sally, VS volunteer)

Consequently, it becomes possible to blame the alcohol rather than the individual for any loss of control. Finney (2004) suggests that "societal and individual beliefs about the links between alcohol and violence may encourage a person to drink to find courage to commit violent behaviour" (p. 5). It is possible, however, that men with a tendency to be violent may drink so as to provide themselves with a ready-made excuse for their behavior (Ollett, 1994, cited in Finney, 2004). This latter point seems also to be borne out by some of Jeff Hearn's (1998) research in which one of his interviewees claimed, "I did use 
alcohol as an excuse, like a vehicle, so that I could do it. To give me an excuse in my own head, saying 'Oh I've had a drink.' But it were an excuse for me to do it, that's all' (p. 141). Nancy Hirschmann (1997) supports these ideas and suggests that men's violence is not viewed as a choice:

Men routinely blame their violence on alcohol, on women's nagging or deficiencies as wife and mother. And of course such men rarely see that they have chosen to subscribe to rigid sex roles that legitimize violence, but rather consider such values to be a factual account of the natural order of things. (p. 203)

As suggested from the volunteer discourses, these excuses seem to have become an integral part of the way society views violent behavior in general and men's violent behavior in particular. However, alongside the volunteers suggesting that men experience decreased self-control as a result of alcohol comes the idea that women need to adapt or modify their own behavior, whether or not they are the ones doing the drinking. In a potentially violent domestic situation, for example, this might mean that women need to avoid any form of nagging behavior. Thus,

[It] was his drink thing you see? And she would just go on and on niggling him, until eventually he would umm I don't say he actually hit her but he sort of would throw [her] against the wall. (Edna, VS volunteer)

Whereas Yvonne, who had herself experienced a violent relationship, said,

Well — the girl across the road, I mean she knew what was going on, and ... she used to say to me "well don't speak to him when he's drunk, you know, and then he won't go back at you." And I said well, "yeah, probably I am winding him up then.” But then I should have a right to say to him, "you're a drunken bastard" [laughter]. You know? .. . but at the start, he was drunk and of course I used to get on my high horse with him, and of course that would make it worse and then bop! But then you-I think you get to listen to the signs and you think, "well when he's drunk, you don't say nothing." (Yvonne, VS volunteer)

Despite learning to say nothing, however, the violence continued for 4 or 5 years until eventually Yvonne left him.

So, as Radford and Stanko (1996) suggest, domestic violence tends to be presented as "either a reflection of bad marital relations, personality disputes, or intoxicating substances, not the manifestation of unequal power and a need to control" (p. 77). Also, the theme of gaining and losing self-control, as Eisikovits and Buchbinder (1999) argue, becomes a "central motif in the metaphoric world of battered women . . (where) her sense of survival is based on her sense of self-control over her and his violence" (p. 860). The woman shoulders the burden of controlling her partner's violence, by first controlling her own speech, actions, or demeanor. 
"She went back." Whether women choose to stay, leave, or return has to be understood in terms of contextual factors and specific life circumstances that influence their decisions (see Baker, 1997; Barnett, 2000; Eisikovits \& Buchbinder, 1999; Lempert, 1997). Often women are expected to adhere to a dominant cultural script that directs them to get away and stay away from their abusers (Baker, 1997). Although the volunteers appeared to try to understand and support women's choices, it was also apparent that they experienced dilemmas in relation to this. On one hand, they denied any attribution of blame (and actively sought to support the victim in avoiding this), yet they also revealed that they expected women to avoid any situation that could possibly be violent. This is amply illustrated by the following:

Researcher: Do you find it frustrating when they go back? Like this woman (client) who went back the first time?

Olive: No, no. Because I think, at the end of the day . . you cannot tell people how to live their lives. You cannot do that. You've just got to be there for them. That is what you are there for. Just to help them and put them in the right direction for help. It has to be their decision at the end of the day. And I always said to her you know "whatever happens, you know, if, if you go back to [him], that is your decision" and umm that's what she did, as I said, she went back. But then she realized that it wasn't gonna work out and left again. [But at least then] it was her final decision. (Olive, VS volunteer; our emphasis)

However, as the interview proceeded, the same volunteer made the following comment regarding the well-publicized violence between the English ex-footballer, Paul Gascoigne, and his then wife, Sheryl:

And I think she had a pretty raw deal . . . but on the other hand, so did he, because you [sic] knew he was violent, but again she kept going back for more, didn't she? And she married him knowing how violent he was. (Olive, VS volunteer; our emphasis)

It was evident from this narrative that to Olive, at least, Sheryl Gascoigne had to accept some responsibility for what happened to her. To make a woman shoulder responsibility for abuse because she "went back for more," for not leaving the domestic situation, or for marrying the man (with a known history of violence) is problematic. It also suggests that there was a degree of consent in her abuse because the victim has the option of leaving the situation but chooses not to. In their research with domestic violence victim advocates in the United States, Dunn and Powell-Williams (2007) explore the tensions inherent in reconciling victim ideology with victim behavior. They argue that victim advocates help battered women to recognize their options and choose to leave. However, they argue that

the language the advocates use inevitably places decision-making in the hands of the clients. It is the women, not their abusers, whom they expect . . . to make the changes 
and ... the only choice the advocates see as appropriate, the only acceptable agency, is leaving the violent relationship. (Dunn \& Powell-Williams, 2007, p. 993)

Looking at a similar issue but from the perspective of the victim, Phyllis Baker (1997) argues that often the dominant cultural script directs women to get away and stay away from their abusers, but in her own research she found that women victims felt that the script was too narrow and did not sufficiently reflect the complexities of their decision to stay with the abuser (Baker, 1997; also see Peled, Eisikovits, Enosh, \& Winstok, 2000). In her article, "Feminism and Power," Ann Yeatman (1997) argues that it is not so much a case of consent "but a complex psycho-dynamic process whereby battered women do not possess any sense of efficacious independent agency in the face of continuing presence of their abusive male partner," their agency being continuously eroded through physical force, unequal power relations, and "a need to control" (p. 150).

Despite the training received by these volunteers, there seemed on the part of some to be a failure to recognize the myriad and complex reasons for a woman remaining with, or returning to, a violent partner. For example, women may find it difficult to leave an abusive relationship because the perpetrators often isolate and undermine women, thus rendering them dependent. "Some women attempting to survive and cope in such circumstances may feel that staying with their violent partner will appease him and thus lessen the violence" (Hester, Pearson, \& Harwin, 1998, p. 22). Often, of course, the victim may continue to have positive feelings for her abuser. Westlund (1999) points out that

in between periods of high tension ... life may take on a semblance of normality, giving the battered woman hope that future bouts of violence can be avoided and that the peace will hold. Women living in such conditions may even come to see their batterers as the bearers of mercy, the source of their happiness as well as their misery. (p. 1047)

Furthermore, as Dobash and Dobash (1992) note, women's reluctance to take action and to report the abusive men

is often exacerbated by social, medical and legal institutions whose actions reveal a powerful legacy of policies and practices that explicitly or implicitly accept or ignore male violence and/or blame the victim and make her responsible for its solution and elimination. (p. 4)

So women victims are expected to "remove themselves from the situation":

I mean nothing is excusable. But I think there are some women that really sort of, you know, irritate. Well it—it's just tension, isn't it? You know tension will grow umm and women won't remove themselves from the situation.... Well I think some women goad men into turning violent. You know when they belittle them and ... but this is to people that are not normally violent. (Edna, VS volunteer; our emphasis) 
This means that the victims are considered to be the ones who have to change their lives and adapt themselves to the domestic situation, the ones who have to look for a solution to their problem (e.g., of being irritating). In extreme circumstances, the woman is often obliged to move away from her home to live away from the aggressor, who normally continues to stay at home, at least in the beginning. An NCH Action for Children Survey in the United Kingdom pointed out that $58 \%$ of women did not want to leave home as opposed to $49 \%$ who said that they had no place to go to (Hester et al., 1998).

These attitudes enable male perpetrators to project their violence as rational and justified. In an in-depth study conducted with 33 domestically violent heterosexual men in the United States, Anderson and Umberson (2001) suggest that some men often depict their partner's acts as "irrational and hysterical" to "justify their own violence and present themselves as calm, cool and rational men" (p. 365). Men described actions such as "[I] grabbed her and threw her down" or "sat on her" as "nonviolence" and "controlled" as opposed to the "outrageous" behavior of their female partners. In addition, Anderson and Umberson argue that "respondents also shifted blame onto female partners by detailing faults in their partner's behaviors and personalities" (p. 367). Similarly, VS volunteers seemed to imply that if women exercised greater restraint over their own behavior, then situations where violence occurs could be avoided. Moreover, it gives legitimacy to men to exercise their "controlled" power to maintain the gendered patterns of behavior. An uncomfortable idea is that it appears as if the VS volunteers interviewed here assume the power that men exercise (or expect to have) is natural and if the status quo is disturbed (through nagging, for example), then women should feel responsible for the exercise of that power.

The narratives of these volunteers raise an important issue in relation to who blames whom. How volunteers position themselves within discourses of violence is important as they also feed back to interagency policy forums. An ethos of blame/responsibility can be seen as contributing to a culture in which violence is normalized, sustained, and ultimately accepted by default. Also, an understanding of the analytically rigorous literature on sexual violence is right in suggesting that a patriarchal framework is useful to understand the persistence/existence of interpersonal violence and the ways in which men are implicated in sustaining patriarchal discourses.

\section{Surveillance and Normalizing Judgments}

This leads us to our next point that attitudes held by abusers as well as by some statutory and voluntary organizations can place women victims of violence through a regime of regulated behavior and gendered norms. ${ }^{14}$ Andrea Westlund (1999), using Foucault's analysis of power in Discipline and Punish: The Birth of the Prison (1991), ${ }^{15}$ argues that the techniques used to maintain power and control over women (experiencing sexual and domestic violence) are both premodern and modern forms of power. She illustrates her argument by looking at domestic violence within households and battered women's interaction and treatment with modern institutions (police, domestic violence shelters, courts, medical and psychiatric professions). ${ }^{16}$ In cases of domestic violence, the power exercised over women by the "batterer/sovereign" is, Westlund (1999) claims, often "pre-modern" 
in that the techniques used are "intensely corporal and brutal and . . . are wielded in a personal and sporadic rather than an impersonal and meticulous manner" (p. 1045). Corporal punishment, sometimes particularly horrific, is exercised to redress perceived contempt for authority, as illustrated by one of the volunteers talking about a victim of domestic violence, to whom she had provided support:

He didn't treat her very well. Kept her short of money and she had to basically- to get the money it was sexual favors to him ... and she retaliated one day rather than take the beating, and so he poured petrol over her and set her alight. (Olive, VS volunteer)

Another research participant, Yvonne, the volunteer who had also been a victim, described an incident with her ex-husband, who was annoyed at his son using the telephone without his permission:

He just [went up] to Ian [17-year-old son] and punched him in the face. Of course, I jumped up then, in front of Ian, as I had done so many times before. . . . And, of course, Ian then pushed me out the way ... cos [my husband] went for me - and Ian said, "you're never gonna hit her again" and I thought, "this is father and son now fighting" and I thought, "this has got to stop, this has got to stop. I'm not having him hit his son over me." And that's all it was; he hit Ian so that he knew I was going to jump up so he could have a go at me then. (Yvonne, VS volunteer)

This narrative illustrates that corporal punishment can occur directly or indirectly against a loved one. In addition to this premodern form of corporal power, however, there is a degree of close surveillance, which is more akin to the power to be found in some modern institutions such as prisons (Westlund, 1999). This surveillance is not only imposed on battered women by their abusers but requires that they learn to "nicely comport themselves exactly as their oppressors would want," seeking to regain some control over their own lives by "concentrating on the micro-practices of everyday life" (MacCannell \& MacCannell, 1993, p. 211). Furthermore, if she takes the help of professional services outside the household, she is often placed within "new and different sets of power relations" by these institutions and may be pathologized as mentally unstable and incapable of appraising her own situation (Westlund, 1999, p. 1046-1049). Women are advised to "commit to" and work on their relationships, making it difficult for some women to recognize which behaviors they should or should not accept (Fraser, 2005, p. 15). This advice, although well meaning, may serve to reflect the more damaging aspects of societal opinion relating to gendered violence in reiterating the responsibility of the victim. For example, discussing sexual abuse, one of the volunteers commented on the advisability of women wearing certain clothing:

If a woman was walking down the road, if she was dressed in a miniskirt and a tight top, is she to blame? And you know if she was sort of raped or attacked or something 
I wouldn't say she was to blame. ... Her wearing that wasn't the causal factor in her getting attacked. ... But had I sort of known her and was talking to her before she did that, I'd advise her not to do it, just because I'm aware even if she's not the causal factor, the causal factors are in place, they're out there. . . . So I think there's a certain sense of . . perhaps you have to take responsibility for your own safety. (Sam, VS volunteer; our emphasis)

In relation to research and experience in both Britain and the United States, Dobash and Dobash (1992) argue that when women experiencing violence have sought professional help "they have often been blamed for the violence, asked to change their behaviour in order to meet their husband's demands, and had their own concerns and requests deflected or ignored" (p. 231). The police and refuge services are two agencies that are often involved in domestic violence cases (Malos, 2000). However, the growing acceptance of the police as a service provider, rather than a force - a term that more accurately connotes police monopoly of coercive powers - shows the tendencies of agencies to deny issues of structural power and inequality (Patel, 1999).

Even the very terms applied to women who have experienced such violence may be seen as an indication of the imposition of normalizing judgments. The rejection of the victim label by many of the organizations offering help and support to women and its replacement with survivor may impose unwanted subjectivities on those who are already feeling vulnerable and unsure of themselves. On one level, the replacement of victim with survivor is perfectly understandable as the former has become synonymous with blame, largely as a result of the work of the early victimologists (e.g., Von Hentig, 1948; Wolfgang, 1958). By using survivor, therefore, feminists and activists are seeking not only to challenge victim blaming but at the same time are stressing the resistance and coping strategies used by women and children and the extent to which they ensure their own survival (Kelly \& Radford, 1996; Walklate, 2003). Furthermore, as Stanko (1985) points out, "in applying the term "victim' . . one implicitly separates victim from non-victim," and it is this separation that enables theorists to examine victims as a cohesive group to find defining characteristics (p. 13). As this culture of victim blaming has entered public consciousness, women who have been abused have become increasingly reluctant to identify themselves as victims. However, the alternative construction of survivor is also far from ideal for many women. Given the many difficulties faced by those forced to cope with sexual and/or domestic violence, and the high numbers killed through such acts, many feminists contend that women cannot and should not be portrayed either as "inevitable victims or as strong survivors for whom abuse has minimal consequences" (Kelly, Burton, \& Regan, 1996, p. 82).

The position of many support agencies in referring to victim/survivor either as dichotomous positions or as different stages of the same situation tends to be unhelpful for those struggling to deal with their experiences. For those women who believe that they could be or should have been more proactive in dealing with what has happened to them achieving survivor status may seem unattainable, leaving them feeling that they have failed somehow to respond in the way they feel society would expect them to respond. Kelly et al. (1996) 
make similar points, suggesting that the victim/survivor dichotomy places individuals in an either/or position that "misrepresents both material and emotional reality" (p. 91; also see Lamb, 1996, 1999). Walklate (2003) points out that although victim and survivor tend to be presented as opposed, they are not necessarily so, as it is, of course, as "possible to think in terms of an active or passive victim, as it is to identify an active or passive survivor" (p. 36). In addition, though, not only is it possible to criticize the dichotomous construction of victim/survivor but also that used most often by feminists and agencies working with women who have experienced domestic violence, the notion of the victim-to-survivor healing journey. This alternative chronological construction of victim to survivor, in its tendency to presume passivity during the victim stage, ignores the resistance and coping strategies that many women adopt during their abuse (see Kelly et al., 1996). We would like to suggest that the meanings of survivor-victim are ambiguous and context specific, and our intent here is not to resolve these dichotomous constructions (as each category can carry elements of both strength and vulnerability) but to foreground women victims' own definitions of their situation.

\section{Institutional Attitudes}

Increasing structural pressures of state funding have led to a steady professionalization of services and an institutionalization of therapeutic vocabularies (Dunn \& Powell-Williams, 2007; Eisikovits \& Buchbinder, 1999; Kendrick, 1998; Lamb, 1996; Lempert, 1997; Loseke, 2001). As a consequence, not only has there been a steady homogenization of women victims' diverse experiences but also increasingly institutional functioning has come to be privileged over individual needs (Loseke, 2001). Institutional files stand in for real people, which process women victims as data points (Pence, 2005; Pence \& McMahon, 1999).

Often dissimilar events and situations are lumped together in a way that fits a "discursive environment (that) privileges stories featuring the centrality of dangerous violence" (Loseke, 2001, p. 114). This means that women victims are expected to include a theme of violence in their narratives, even though women might want to talk about marital infidelity, a nonappreciative husband and family, or problems related with alcohol abuse.

In our specific research with VS volunteers, we argue that institutional discourses can nurture embedded social norms that enable society to absolve itself of any collective responsibility for tackling interpersonal violence. This is highlighted in institutional texts such as safety advice literature, aimed specifically at women, which embodies institutional thinking.

Although there is unambiguous reference in literature provided by VS to the fact that "[r]ape and sexual assault, whether by a stranger or friend, is never the woman's fault" (VS, n.d.), at the same time the personal-safety information they distribute places emphasis on the need for women to "take care." In a participant observation (2003) of domestic violence training, a male trainee (in his late 50s) who was supported in his views by a female trainee (of a similar age) suggested that young girls and women wearing "revealing clothing" were problematic because culture is making sexuality another commodity"something you can take." 
The literature exacerbates women's fear of crime, not only subjecting women to a form of social control but also under the guise of common sense creates an implicit division between women who follow the advice and those who do not. Gardner (1990) notes that it is "women's alleged responsibility for their own victimization" that results in them having to become "streetwise" and to take a variety of precautions (p. 312). This, we would suggest, maintains the status quo by reiteration of the dominant position - that it is incumbent on women to take precautions rather than on men to take control (Morgan \& Thapar-Björkert, 2006). Thus, we would argue that any real change would also entail making a change in the institutional texts.

The purpose of writing this is not to suggest that professional services should be removed (in fact, rather the opposite), and we recognize the invaluable work conducted by the vast majority of professional organizations and individuals offering support to women who have experienced all forms of violence. We are suggesting, however, that some professional services are in danger of imposing a set of regulatory norms on women and children who have already been subjected to an external and internalized gaze.

\section{Conclusion}

The persistence of interpersonal violence in the experiences of ordinary lives is one of the main reasons for reexploring some of the mechanisms through which women (and men) experience violence. Violence is not the responsibility of women or the result of an individual pathology but a problem of the entire society, particularly the norms and attitudes that harbor prejudices relating to women victims of violence. In reviewing some of the dominant discourses that create, nurture, and sustain violence, we argue that the culture of blame and responsibility disempowers women who experience domestic and sexual violence.

In this article, we have focused on VS in the United Kingdom and suggested that the volunteers are in a unique position to have a greater understanding of the range of harms encompassed by the term violence. However, we argue that some volunteers, through no fault of their own, fail adequately to challenge discourses of blame in relation to women victims of violence because the dominant discourses of victim blame outweigh the new, less popular discourses of nonblame. Often in speech, counter theories are implicit rather than explicit, and the person expressing the discourse may not be aware of these countermeanings in the way that a hypocrite would be (Billig et al., 1988). Thus, although the organizational rhetoric, policies, and measures may provide immediate (and necessary) assistance to the victim, they fall short in addressing or changing wider social attitudes and thus providing permanent safety or genuine empowerment. The tensions between nonblame and responsibility as revealed by the volunteers appear to be part of a wider understanding of how women and men interact. Although there are problems in attributing certain discourses to patriarchal power alone, there does appear to be evidence of dominant discourses and prevalent ideologies, which are a potential source of ambiguity particularly when considering women's experiences of violence. The volunteers, explicitly faced with two opposing ideologies, are perhaps more likely to experience conflicting attitudes than 
most people and are therefore more likely to articulate their ideological dilemmas. The volunteers who participated in this research were attempting to reconcile the opposing discourses to which they were exposed and create a coherent schema. Perhaps, this reconciliation could have become easier if the volunteers had access to a feminist discourse, which has historically encouraged a reflexive practice of the limits of our own approaches in dealing with victims of violence.

There is thus, we suggest, an urgent need for a steady and continuous change in the civic-political culture (broadly understood as a set of institutional, representational, and discursive values held by citizens and among citizens) - a change from the prevalent culture of resignation (Morgan, 2005, 2006). A culture of resignation only reiterates disempowering constructions of blame/responsibility, which do not completely map the complexity or plurality of violence toward women. Our focus should move away from a produced victim to social attitudes that may generate a victim.

\section{Acknowledgment}

We would like to thank the anonymous reviewers for their helpful and insightful comments. The research on which this article is based would not have been possible without the involvement and interest of Victim Support and the volunteers who took part.

\section{Declaration of Conflicting Interests}

The authors declared no potential conflicts of interest with respect to the authorship and/or publication of this article.

\section{Funding}

The authors disclosed receipt of the following financial support for the research and/or authorship of this article: The research on which this article is based was funded by the Economic and Social Research Council (award number R42200134342).

\section{Notes}

1. The network of affiliated charities known collectively as the National Association of Victim Support Schemes originated in Britain in 1973-1974 following the development of the Bristol Victims Support Scheme. Within 4 years, some 30 similar schemes had been set up, and by the late 1990s there were approximately 450 schemes operating throughout England and Wales (National Audit Office, 2002) with the National Office based in London.

2. The issue of obtaining informed consent is an ambiguous one. In conducting "feminist research," which was the intention here, we recognize that "knowledge production [is] ... grounded in individual and collective experiences," and consequently at the outset of the research it is not always completely apparent where it will lead us (Miller \& Bell, 2002, p. 54). So although it is extremely important to explain the research aims to the participants, the findings may not always correspond to the original research aims. Such was the case in this research, which was intended to examine attitudes to women victims of violence and yet which surprised us in revealing the extent to which these VS volunteers possessed simultaneous yet conflicting notions of who was deserving or undeserving of violence. 
3. Collins (1998) points out that using a structured/unstructured dichotomy is ultimately unhelpful when talking about interviews, as the interview situation is always structured to some extent. Mason (2002) also notes that it is not possible to conduct a "structure-free interview not least because the agendas and assumptions of both interviewer and interviewee will inevitably impose frameworks for meaningful interaction" (p. 231).

4. Ricoeur's (1981) science of hermeneutics suggests that there are two types of interpretation, the hermeneutics of faith and the hermeneutics of suspicion. The former can be "construed as the restoration of a meaning addressed to the interpreter in the form of a message. This type of hermeneutics is animated by faith, by a willingness to listen," whereas the latter is "regarded as the demystification of a meaning presented to the interpretation in the form of a disguise. This type of hermeneutics is animated by suspicion, by a scepticism towards the given" (Thompson, 1981, p. 6).

5. At the time the empirical research was conducted (2003-2004) by the second author, VS was a network of affiliated charities, operating under an umbrella organization of Victim Support National Office. In 2003, the government announced plans to direct funding via local Criminal Justice Boards rather than directly to Victim Support (VS). And in May 2007, an extraordinary General Meeting of VS voted overwhelmingly (90\%) in favor of creating a single charity, a process that is now underway (VS, 2007).

6. The Victim's Charter is a statement of service standards for victims of crime (Home Office, 2004) and is available on demand from the Home Office, VS, and police stations. Interestingly, the charter mentions only VS and its Witness Service but ignores organizations such as Women's Aid and Rape Crisis (see Williams, 1999).

7. The Home Office is currently reviewing the service provided to victims of crime in a series of moves that will impact the way in which VS and other organizations operate (see Criminal Justice System, 2005).

8. Victim advocates in the United States work in shelters and criminal justice settings such as the prosecutor's office, police department, and sheriff's office (see McDermott \& Garofalo, 2004).

9. Unless the volunteer has reason to believe that children may be at risk, in which case a decision may be taken to involve social services.

10. We recognize that this experience is shaped by gender, race/ethnicity, religion, class, and sexuality, which are not separate systems of domination or axes of power but are mutually constitutive (Hill Collins, 1998; Mama, 1989). These social divisions can render women of color's experiences as qualitatively different from those of White women (Crenshaw, 1994).

11. Donileen Loseke (2001) argues that "formula stories are narratives about types of experience (such as wife abuse), involving distinctive types of characters (such as battered women and the abusive man)" (p. 107).

12. Both Victim Support National Office and the Home Office consider that "the involvement of members of the community, offering their time free of charge, was vital to the work. Victims did not necessarily want full-time paid professional counselors supporting them but local people" (House of Commons, 2003, p. 8). This means, however, that the quality and extent of service available can vary significantly from area to area, although there are significant moves underway to ensure that all areas reach the same high standards. 
13. It is difficult to say how these views of VS workers were reflected in their practices with victims, but the second author observed several training sessions between volunteers, VS training staff, and trainers from external professional training organizations. In these situations, all of them upheld the principles of nonblame, active listening, and nonjudgmental support. All volunteers interviewed indicated a willingness to comply with these rules in practice.

14. Other research has recognized that institutions can be as "violent and intimidating as individuals" (Hanmer \& Maynard, 1987, p. 5). For example, Amina Mama (1989) argues that multiagency responses in the United Kingdom to battered Black women (Asian, African, and Caribbean), in particular, aggravate their suffering and isolation. Many Black women are often coerced into a relationship with social services, which adds "to their oppressions of violence, homelessness and racism by further disempowering rather than supporting the women" (Mama, 1989, p. 96). Also, in the British context, many women of African, Asian, and Caribbean descent would not access the "palliative" measures because of the stereotypes and preconceptions associated with their ethnicity (Mama, 1989, p. 24).

15. Michel Foucault in Discipline and Punish (1991) suggests that premodern power is characterized by using violence that is intensely corporal and brutal and wielded in a personal manner. Modern power is defined by using violence in a more anonymous, invisible, and lighter way. Disciplinary institutions and practices would follow this pattern, which is less violent and more invisible and diffuse but extremely invasive.

16. Different disciplines studying the problems associated with violence, such as medicine, psychology, psychiatry, and legal studies, have been redescribing women's abnormalities, pathologizing women who are victims of male dominance, created and supported the same time by patriarchal cultures that allow female domination (Caplan, 1991).

\section{References}

Anderson, K., \& Umberson, D. (2001). Gendering violence: Masculinity and power in men's accounts of domestic violence. Gender \& Society, 15, 358-380.

Baker, L. P. (1997). “And I went back”: Battered women's negotiation of choice. Journal of Contemporary Ethnography, 26, 55-74.

Barnett, O. W. (2000). Why battered women do not leave, Part 1: External exhibiting factors within society. Trauma, Violence and Abuse, 1, 343-372.

Berns, N. (2001). Degendering the problem and gendering the blame: Political discourse on women and violence. Gender \& Society, 15, 262-281.

Berns, N., \& Schweingruber, D. (2007). "When you're involved, it's just different": Making sense of domestic violence. Violence Against Women, 13, 240-261.

Billig, M., Condor, S., Edwards, D., Gane, M., Middleton, D., \& Radley, A. (1988). Ideological dilemmas: A social psychology of everyday thinking. London: Sage.

Birch, M., \& Miller, T. (2000). Inviting intimacy: The interview as therapeutic opportunity. International Journal of Social Research Methodology, 3, 189-202.

Boateng, P. (1999, November 24-25). Living without fear: An agenda for action. Speech made at the Home Office Special Conference on Violence Against Women. Retrieved March 1, 2007, from http://www.homeoffice.gov.uk/dometsicviolence/pbspeech.htm 
Bunch, C., \& Carrillo, R. (1992). Gender violence: A development and human rights issue. Dublin, Ireland: Attic Press.

Caplan, P. (1991). How do they decide who is normal? The bizarre but true tale of the DSM process. Canadian Psychology, 32, 162-170.

Collins, P. (1998). Negotiating selves: Reflections on "unstructured" interviewing. Sociological Research Online, 3. Retrieved from November 2, 2009, http://www.socresonline.org.uk/ 3/3/2.html

Corrin, C. (Ed.). (1996). Women in a violent world: Feminist analyses and resistance across Europe. Edinburgh, UK: Edinburgh University Press.

Cosgrove, K. (1996). No man has the right. In C. Corrin (Ed.), Women in a violent world: Feminist analyses and resistance across Europe (pp. 186-203). Edinburgh, UK: Edinburgh University Press.

Crenshaw, K. W. (1994). Mapping the margins: Intersectionality, identity politics and violence against women of color. In M. Fineman \& R. Mykitiuk (Eds.), The public nature of private violence (pp. 93-121). New York: Routledge.

Criminal Justice System. (2005). Rebuilding lives: Supporting victims of crime. London: HMSO.

Dobash, R. E., \& Dobash, R. P. (1992). Women, violence and social change. London: Routledge.

Dobash, R. E., \& Dobash, R. P. (1997). Violence against women. In L. O’Toole \& J. R. Schiffman (Eds.), Gender violence: Interdisciplinary perspectives (pp. 266-279). New York: New York University Press.

Dunn, L. J., \& Powell-Williams, M. (2007). "Everybody makes choices": Victim advocates and the social construction of battered women's victimization and agency. Violence Against Women, 13, 977-1001.

Eisikovits, Z., \& Buchbinder, E. (1999). Talking control: Metaphors used by battered women. Violence Against Women, 5, 845-868.

Fairclough, N. (1995). Critical discourse analysis: The critical study of language. London: Longman.

Field, C. A., Caetano R., \& Nelson, S. (2004). Alcohol and violence related cognitive risk factors associated with the perpetration of intimate partner violence. Journal of Family Violence, 19, 249-253.

Finney, A. (2004). Alcohol and intimate partner violence: Key findings from the research. London: Home Office, Communications Development Unit.

Foucault, M. (1991). Discipline and punish: The birth of the prison. London: Penguin.

Fraser, H. (2005). Women, love, and intimacy "gone wrong": Fire, wind and ice. Affilia, 20(1), 10-20.

Gardner, C. B. (1990). Safe conduct: Women, crime and self in public places. Social Problems, 37, 311-327.

Hague, G. (1998). Interagency work and domestic violence in the UK. Women's Studies International Forum, 21, 441-449.

Hague G., \& Mullender, A. (2006). Who listens? The voices of domestic violence survivors in service provision in the United Kingdom. Violence Against Women, 12, 568-587.

Hanmer, J., \& Maynard, M. (Ed.). (1987). Women, violence and social control. London: Macmillan. 
Hearn, J. (1998). The violences of men: How men talk about and how agencies respond to men's violence to women. Sage: London.

Hester, M., Kelly, L., \& Radford, J. (Eds.). (1996). Women, violence and male power. Buckingham, UK: Open University Press.

Hester, M., Pearson, C., \& Harwin, N. (1998). Making an impact: Children and domestic violence. A reader. Essex, UK: Barnardo's.

Hill Collins, P. (1998). It's all in the family: Intersections of gender, race and nation. Hypatia, $13,62-82$.

Hirschmann, N. J. (1997). Toward a feminist theory of freedom. In M. L. Shanley \& U. Narayan (Eds.), Reconstructing political theory: Feminist perspectives (pp. 195-210). Cambridge, UK: Polity.

Holstein, J. A., \& Gubrium, J. F. (2000). The self we live by: Narrative identity in a post-modern world. New York: Oxford University Press.

Home Office. (2004). The Victim's Charter: A statement of service standards for victims of crime. London: Criminal Justice System.

hooks, b. (1997). Violence in intimate relationships: A feminist perspective. In L. O'Toole \& J. Schiffman (Eds.), Gender violence: Interdisciplinary perspectives (pp. 279-285). New York: New York University Press.

House of Commons, Committee of Public Accounts. (2003). Helping victims and witnesses: The work of victim support (Seventeenth Report of Session 2002-2003). London: Stationery Office Limited.

Josselson, R. (2004). The hermeneutics of faith and the hermeneutics of suspicion. Narrative Inquiry, 14, 1-28.

Kelly, L. (1988). Surviving sexual violence. Cambridge, UK: Polity.

Kelly, L. (1996). When does the speaking profit us? Reflections on the challenges of developing feminist perspectives on abuse and violence by women. In M. Hester, L. Kelly, \& J. Radford (Eds.), Women, violence and male power: Feminist activism, research and practice (pp. 34-49). Buckingham, UK: Open University Press.

Kelly, L., Burton, S., \& Regan, L. (1996). Beyond victim or survivor: Sexual violence, identity and feminist theory and practice. In L. Adkins \& V. Merchant (Eds.), Sexualizing the social: Power and the organization of sexuality (pp. 77-101). Basingstoke, UK: Macmillan Press.

Kelly, L., \& Radford, J. (1996). "Nothing really happened." The invalidation of women's experiences. In M. Hester, L. Kelly, \& J. Radford (Eds.), Women, violence and male power (pp. 19-33). Buckingham, UK: Open University Press.

Kendrick, K. (1998). Producing the battered woman: Shelter politics and the power of feminist voice. In N. Naples (Ed.), Community activism and feminist politics: Organizing across race, class and gender (pp. 151-173). New York: Routledge.

Lamb, S. (1996). The trouble with blame: Victims, perpetrators and responsibility. Cambridge, MA: Harvard University Press.

Lamb, S. (1999). Constructing the victim: Popular images and lasting labels. In S. Lamb (Ed.), New versions of victims: Feminists struggle with the concept (pp. 108-139). New York: New York University Press.

Lea, J. S. (2007). A discursive investigation into victim responsibility in rape. Feminism and Psychology, 17, 495-514. 
Lempert, L. B. (1997). The other side of help: Negative effects in the help-seeking processes of abused women. Qualitative Sociology, 20, 289-308.

Loseke, D. R. (1992). The battered woman and shelters: The social construction of wife abuse. Albany: State University of New York Press.

Loseke, D. R. (1999). Thinking about social problems: An introduction to constructionist perspectives. New York: Aldine de Gruyter.

Loseke, D. R. (2001). Lived realities and formula stories of "battered women.” In J. F. Gubrium \& J. A. Holstein (Eds.), Institutional selves: Troubled identities in a post-modern world (pp. 107-126). New York: Oxford University Press.

MacCannell, D., \& MacCannell, J. F. (1993). Violence, power and pleasure: A revisionist reading of Foucault from the victim perspective. In C. Ramazanoğlu (Ed.), Up against Foucault: Explorations of some tensions between Foucault and feminism (pp. 203-238). London: Routledge.

Malos, E. (2000). Supping with the devil?: Multi-agency initiatives on domestic violence. In J. Radford, L. Harne, \& M. Friedberg (Eds.), Women, violence and strategies for action: Feminist research, policy and practice (pp. 120-136). Buckingham, UK: Open University Press.

Mama, A. (1989). The hidden struggle: Statutory and voluntary sector responses to violence against Black women in the home. London: London Race and Housing Research Unit.

Mason, J. (2002). Qualitative interviewing: Asking, listening and interpreting. In T. May (Ed.), Qualitative research in action (pp. 225-241). London: Sage.

Maynard, M. (1993). Violence towards women. In D. Richardson \& V. Robinson (Eds.), Introducing women's studies: Feminist theory and practice (pp. 99-122). London: Macmillan.

McDermott, J. M., \& Garofalo, J. (2004). When advocacy for domestic violence victims backfires: Types and sources of victim disempowerment. Violence Against Women, 10, $1245-1266$

McLaughlin, J. (2003). Feminist social and political theory: Contemporary debates and dialogues. New York: Palgrave Macmillan.

Mezey, G., \& Stanko, E. (1996). Women and violence. In K. Abel, M. Buszewicz, \& E. Staples (Eds.), Planning community mental health services for women: A multiprofessional handbook (pp. 160-175). Routledge: London.

Miller, T., \& Bell, L. (2002). Consenting to what? Issues of access, gate-keeping and "informed" consent. In M. Mauthner, M. Birch, \& T. Miller (Eds.), Ethics in qualitative research (pp. 53-69). London: Sage.

Morgan, K. (2005). Violence against women: The discursive construction of a culture of resignation. Unpublished doctoral thesis, University of Bristol, UK.

Morgan, K. (2006). Cheating wives and vice girls: The construction of a culture of resignation. Women's Studies International Forum, 29, 489-498.

Morgan, K., \& Thapar-Björkert, S. (2006). "I'd rather you'd lay me on the floor and start kicking me": Understanding symbolic violence in everyday life. Women's Studies International Forum, 29, 441-452.

National Audit Office. (2002, 23 October). Helping victims and witnesses: The work of Victim Support (2001-2002) (Report by the Comptroller and Auditor-General HC1212. Session 2001-2002). London: The Stationery Office. 
National Statistics Online.(2001). Neighbourhoodstatistics: Neighbourhoodprofile. Retrieved 30 March, 2005, from http://www.neighbourhood.statistics.gov.uk/dissemination/AreaProfile2 .do?tab=2

Ollett, B. (1994, April). Alcohol and crime: A Women's Aid perspective: Causes of domestic violence. Paper presented at the conference From Problems to Solutions: Alcohol and Crime, Carmarthen, UK.

Pahl, J. (Ed.). (1985). Private violence and public policy: The needs of battered women and the response of the public services. London: Routledge.

Patel, P. (1999). The multi-agency approach to domestic violence: A panacea or obstacle to women's struggles for freedom from violence. In N. Harwin, G. Hague, \& E. Malos (Eds.), The multi-agency approach to domestic violence: New opportunities, old challenges? (pp. 172-190). London: Whiting and Birch.

Peled, E., Eisikovits, Z., Enosh, G., \& Winstok, Z. (2000). Choice and empowerment for battered women who stay: Towards a constructivist model. Social Work, 45, 9-25.

Pence, E. (2005, March). Violence against women: Coordinating activism, research and service provision conference. Plenary at the ESRC seminar, University of Bristol, UK.

Pence, E., \& McMahon, M. (1999). Duluth: A coordinated community response to domestic violence. In N. Harwin, G. Hague, \& E. Malos (Eds.), The multi-agency approach to domestic violence: New opportunities, old challenges? (pp. 180-194). London: Whiting and Birch.

Radford, J., \& Russell, D. E. H. (Eds.). (1992). Femicide: The politics of woman killing. Buckingham, UK: Open University Press.

Radford, J., \& Stanko, E. A. (1996). Violence against women and children: The contradictions of crime control under patriarchy. In M. Hester, L. Kelly, \& J. Radford (Eds.), Women, violence and male power (pp. 142-157). Buckingham, UK: Open University Press.

Ricoeur, P. (1981). Hermeneutics and the human sciences. Cambridge, UK: Cambridge University Press.

Rothenberg, B. (2003). "We don't have time for social change": Cultural compromise and the battered woman syndrome. Gender \& Society, 17, 771-786.

Smart, C. (1989). Feminism and the power of law. London: Routledge.

Smart, C., \& Smart, B. (1978). Accounting for rape: Reality and myth in press reporting. In C. Smart \& B. Smart (Eds.), Women, sexuality and social control (pp. 10-23). London: Routledge.

Spackman, P. (2000). Victim support handbook: Helping people cope with crime. London: Hodder and Stoughton.

Stanko, E. A. (1985). Intimate intrusions: Women's experience of male violence. London: Routledge.

Stanko, E. A. (1990). When precaution is normal: A feminist critique of crime prevention. In L. Gelsthorpe \& A. Morris (Eds.), Feminist perspectives in criminology (pp. 171-183). Milton Keynes, UK: Open University Press.

Stanko, E. A. (Ed.). (2003). The meanings of violence. London: Routledge.

Stanko, E. A. (2006). Theorizing about violence: Observations from the Economic and Social Research Council's Violence Research Programme. Violence Against Women, 12, 543-555.

Thompson, J. B. (1981). Critical hermeneutics: A study in the thought of Paul Ricoeur and Jürgen Habermas, Cambridge, UK: Cambridge University Press. 
Tisdall, E. K. M. (2003). The rising tide of female violence? Researching girls' own understandings and experiences of violent behavior. In R. M. Lee \& E. A. Stanko (Eds.), Researching violence: Essays on methodology and measurement (pp. 137-153). London: Routledge.

Titscher, S., Meyer, M., Wodak, R., \& Vetter, E. (2000). Methods of text and discourse analysis. London: Sage.

Van Dijk, T. A. (1997). Discourse as interaction in society. In T. A. van Dijk (Ed.), Discourses as social interaction (pp. 1-37). London: Sage.

Victim Support. (n.d.). Rape and sexual assault: Information for women. London: Author.

Victim Support. (2003). Resource pack for supporting victims of domestic violence. London: Victim Support National Office.

Victim Support. (2005). Service Personnel and Equal Opportunities Survey report 2004. London: Victim Support National Office, Research and Development Department.

Victim Support. (2006). Victim and witness review: Annual report and accounts. London: Author.

Victim Support. (2007). Handbook on delivering Victim Support's enhanced services (Interim version). London: Victim Support National Office.

Victim Support Magazine. (1998, Autumn). London: Author.

Von Hentig, H. (1948). The criminal and his victim. New Haven, CT: Yale University Press.

Walklate, S. (2003). Can there be a feminist victimology? In P. Davies, P. Francis, \& V. Jupp (Eds.), Victimisation: Theory, research and policy (pp. 28-45). Basingstoke, UK: Palgrave Macmillan.

Weaver, C. K. (1998). Crimewatch UK: Keeping women off the streets. In C. Carter, G. Branston, \& S. Allan (Eds.), News, gender and power (pp. 248-262). London: Routledge.

Westlund, A. (1999). Pre-modern and modern power: Foucault and the case of domestic violence. Signs, 24, 1046-1066.

Williams, B. (1999). The Victim's Charter: Citizens as consumers of criminal justice services. Howard Journal, 38, 384-396.

Wodak, R. (1996). Disorders of discourse. London: Longman.

Wolfgang, M. E. (1958). Patterns in criminal homicide. Philadelphia: University of Pennsylvania Press.

Yeatman, A. (1997). Feminism and power. In M. L. Shanley \& U. Narayan (Eds.), Reconstructing political theory: Feminist perspectives (pp. 144-157). Cambridge, UK: Polity.

\section{Bios}

Suruchi Thapar-Björkert is a senior lecturer at the University of Bristol in the Department of Sociology. Her research interests are gendered discourses of colonialism and nationalism; gendered violence in India and Europe; and gender, social capital and social exclusion, and qualitative research methodologies.

Karen J. Morgan is currently working at Cardiff University on a research project assessing the impact and effectiveness of the ethical framework for local government in England. Her main areas of interest are concerned with empirical and theoretical research into gendered and symbolic violence, print media analysis, and issues around ethical veganism and animal rights. 